Scientific Journal of the Faculty of Fine Arts Alexandria University

\title{
An Assessment Framework for Time Based Vitality of Public Parks
}

\author{
Y. Megahed ${ }^{1}$, A. ED. Sarhan², Y. Farghaly²
}

\begin{abstract}
Public parks act as a catalyst for assuring the enhancement of life quality and community performance since they are considered as an integral part of the urban fabric. Parks have a vital performance in creating communities of lasting values. They bring nature to the city, enable social interaction, and create environmentally and economically resilient communities. Vitality of parks is related to the park's strength, interaction of users at different times and the variety of facilities. Vitality has four dominant factors: accessibility, legibility, convenience, and distinctiveness. The diurnal and nocturnal state of the parks is the reason behind its dynamic vitality, as well as the difference in seasons, and this proves that time is a relevant dimension in analyzing the vitality of public parks, which forms the research problem. Therefore, the research aims to determine the impact of time on vitality of parks in relation to the factors' physical and social attributes. The study focuses on vitality factors and time impact on each one, resulting in different park patterns. The researcher concluded a framework that complies the impact of time on the four vitality parameters with their attributes, then applied it on an analytical example of public parks.
\end{abstract}

KEYWORDS: Public parks, Vitality of parks, Nighttime in parks, Time impact on parks.

\section{INTRODUCTION}

Urban green space is not about only trees and benches; it is unlike the meaning that might be created in mind. It symbolizes the cultural and social thoughts of a community or a society and listed from the most vital factors in urban fabric. A significant part of urban green spaces is created in parks. Urban parks act as a mandatory part of urban infrastructure, in addition to improving the quality of life by providing social and environmental facilities [1]. Vitality in urban public parks indicates a safer and welcoming environment that offers more varieties for social activities and cultural exchange [2]. It means a state of dynamism and interaction between the environment and users [3]. Vitality is described by

\footnotetext{
${ }^{1}$ Part time teacher assistant, Architectural Engineering \& Environmental Design Department, Arab Academy for Science, Technology \& Maritime Transport, Abukir Campus, Alexandria, Egypt yosramegahed@gmail.com

${ }^{2}$ Professor, Architectural Engineering \& Environmental Design Department, Arab Academy for Science, Technology \& Maritime Transport, Abukir Campus, Alexandria, Egypt
} 


\section{SJFA}

Scientific Journal of the Faculty of Fine Arts Alexandria University

Lynch (1981) as one of the performance dimensions of urban design as well as the degree to which the form of places promotes the functions, biological requirements and effectiveness of human beings $[2,4]$.

\section{METHODOLOGY}

The paper starts fistly with predominant data which is covered in the literature review from published literatures as in journals or conferences, and then determining vitality definition, its characteristics and the effect of time on vitality of public parks. This is followed by analysing an example which is selected based on their geographical location, scale and presence of enough data for measuring the impact of time on their vitality performance.

\section{LITERATURE REVIEW}

In the urban context, vitality is considered a crucial quality as it enhances passive enjoyment of streetscape, strengthen social interaction, abates crime as well as allowing cultural exchange [2]. It is one of the criteria that effects the environmental quality of an urban public space. Being vital is translated into the social relations of people in the space; therefore, the community can be deliberated as one of the vitality norm indicators in urban design [5]. "Vitality" is used to measure the intangible benefits of the urban parks and construct an approach to assess the park vitality.

\subsection{Vitality definition}

Park vitality is defined as the liveliness that attracts urban residents to use the recreational services due to the richness of the landscape, accessibility of the park and diversity of functions [6]. Gehl (1996) states that vibrant active spaces are those where optional and social activities occur during an extended range of time [9]. Gehl considers the success of public space is a result of its vitality. He believes that vitality of public space covers physical, management, geographical, emotional and psychological aspects [10]. Therefore, urban vitality is the latest goal of modern urban sustainable development [11]. Figure (1) lists the criteria used to measure vitality of an urban space according to five urban planners.
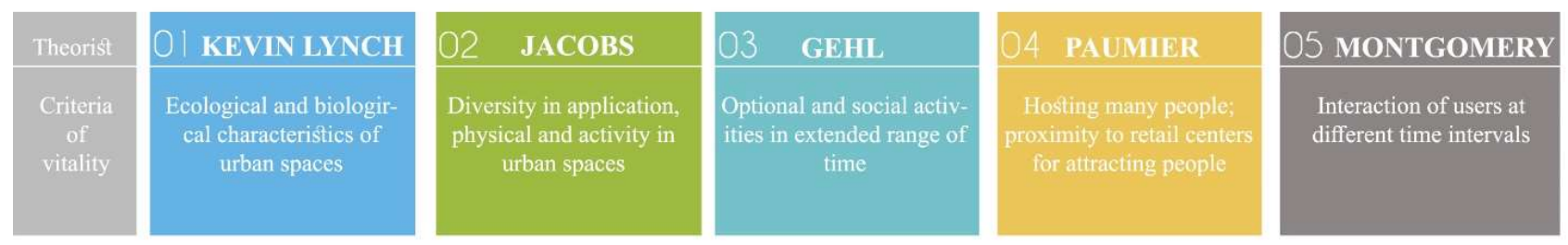

Fig. 1. Vitality criteria of five urban planners. Source: [9]

According to the variety of definitions given to vitality, a vital urban space is where significant number of individuals with variable age and sex during an entire day whose activities and interaction could be observed [5]. The space should meet the users' needs and comfort during their entire day time stay $[5,12]$. As the term urban vitality has been used widely in different topics, its meaning can be referred to the capacity of inducing lively businesses and human activities [13]. The user's ability to understand the physical environmental perceptions of a space is a significant factor for attracting individuals' attention. As a result, there should be a welcoming and appealing atmosphere and attractive elements to enhance their stay while being satisfied $[5,14]$.

\subsection{Characteristics of vitality}

An experience of vitality can be expressed by time, space, power and intention [12]. Rastegar et. al (2014), stated that vitality is concerned with four different features; levels of activities, levels of use, 
levels of interaction and communication and levels of representation, which shows how activity, use and interaction are projected outwards [3,15]. Vitality describes the flow of activities and how dynamic the place is. A socially vital and viable place would be defined by strong social cohesion, mobility between different social levels, vibrant society, good communication and low levels of deprivation [15].

Inclusive design in public parks aims to equalize usage by all sectors of society. Researchers identified three inclusive needs levels: safety (high priority), accessibility (moderately-high), and regular maintenance (average) [16]. There are three categories of physical characteristics contributing to vitality. The first is climatic comfort; by providing light, shadow and protection against wind. The second is creating sense of safety and security, and the third category refers to environmental features stimulating an aesthetic sense in individuals [4]. Vitality of public spaces is impacted by variety of factors based on different urban planners' viewpoints such as; legibility, security, spatial diversity, sense of place, accessibility, variety of activities, environmental attention and seating areas [7].

\subsection{Key components of vitality}

Park vitality counts on users' actual contact with the park, utilization of variety of recreational activities and to what extent are the individuals satisfied with their recreational experiences. The greater visiting intensity of the urban park and the higher degree to which the visitors' recreational demands are met, the more vital the park would be [6]. A vibrant urban space can easily be impacted by certain factors, such as; accessibility, diversity, aesthetic elements, security and climatic comfort [17]. Parks' usage is reflected on quality of life by increasing the degree of enjoyment and satisfaction experienced daily $[18,19]$.

\subsubsection{Accessibility}

Accessibility of urban parks is a necessary indicator reflecting how much the facilities within parks are enjoyed in a convenient way by the citizens [20]. Access to urban parks and greenspaces increase the variety of physical activities in urban societies [21]. To optimize park usage, especially for compact megacities, it is crucial to determine the ease of access to parks [22]. Circulation is the potential channel of the users' flow from outside to inside of the park. According to Lynch (1960), paths are the predominant elements in the image of a site. Abu Bakar, J. (2002) has cited from Baljon, (1992) that good accessibility and linkage includes ease of visiting the parks by various means of transportation and functional coherence between inside of the park and the immediate surroundings [23].

Accessibility is a complex definition that relies on both physical and socio-cultural factors. Parks have to be physically and socially accessible [24-25]. An accessible park has various criteria including linkages, walkability, connectedness and convenience [26]. Park size, park location, park context and public transportation have a huge influence on accessibility of park and number of visits [27]. The most important factors influencing perceived accessibility to urban parks are physical and locational features such as proximity to the park, a pleasant walking experience and a sufficient number of parks in the neighborhood [28]. Proximity of parks have been adopted as one of the key driving factors in stimulating the dynamic process and complex of urban land use [29].

\subsubsection{Legibility}

Lynch (1960) describes the concept of legibility as the identifiable and coherent structure of constituents and the characteristics of being clear enough to be understood [30-32]. Legibility is one of the key features that is directly related to the utilization and recognition of a park. It expresses the environmental characteristics that enable to create and organize a cognitive map [31]. Based on Lynch definition, legibility is a physical and spatial characteristic of the environment, where it enhances the structure, identity and meaning of environmental surrounding [33]. According to Gehl (1971), legibility 


\section{SJFA}

Scientific Journal of the Faculty of Fine Arts Alexandria University

is determined by the quality of built environment, its clarity, simplicity, continuity, rhythm and the dominance of unity with all the setting elements. Legible spaces augment the relationship between environment and users, supporting social connectedness by strengthening the users' attention and clarifying their perception and mental cognition towards the space [30].

The main reason behind underutilized parks is due to park elements that are not appealing and legible, therefore legibility attributes covers clear structure, visual obstacles and accessibility [34]. Comfort, cleanliness, safety and security, attractiveness and sustainability are mainly used to evaluate legibility of the space and user satisfaction [35]. Comfort and image have employed three dimensions; park furniture; the place of seating areas, maintenance and safety of park [23]. The below figure clarifies each dimension.

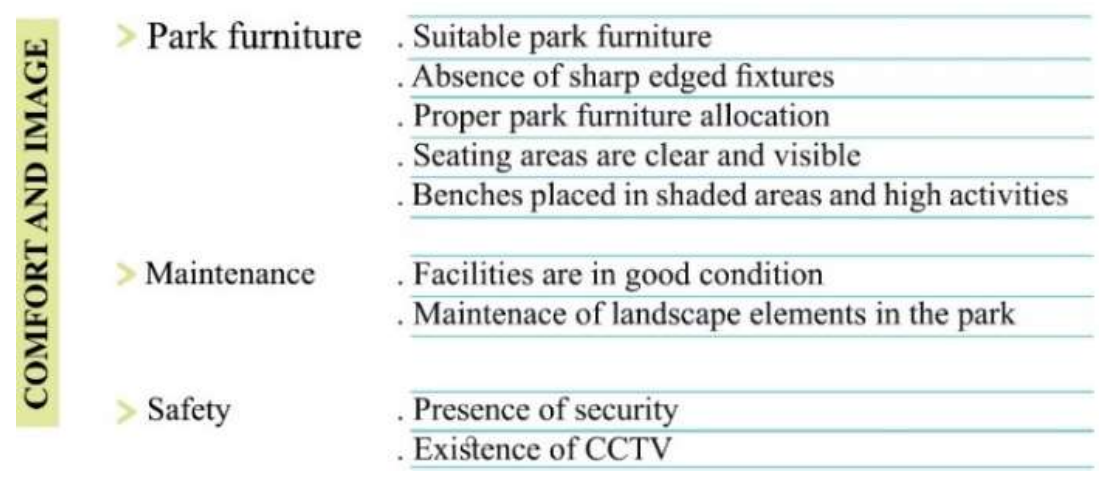

Fig. 2. Attributes of Comfort and Image. Source: [29]

Regarding safety of parks, there are eight themes that applies to sense of insecurity and fear of crime, known as perceived safety, which are concealment of views, being alone, signs of physical disorder, presence of social incivilities, familiarity, prior information about crime, previous crime experience and maintained vegetation [36]. There are three groups associated with perceived safety in urban parks; personal, social and physical attributes [37]. Personal attributes as age and gender, social attributes are related to number of psychological aspects; social relations between people and social incivilities, while physical attributes are aspects that might induce fear as low lighting, physical incivilities such as graffiti, vandalism or trash, concealment of view due to landscape, way finding and legibility and maintenance [36-38]. Findings by some researchers also stated that the time, day or night, as well as the season are associated with sense of crime in urban green spaces [39].

The main reasons of lighting green areas are raising the sense of safety, improving security, maintaining the continuity of communication corridors after dark, create appealing landscape with light and facilitating longer activity and recreation in the park. Planning the light of green spaces is an effective consequence in seeking the balance between urban and natural environment [40]. Good illumination of the park increases its vitality as users tend to visit it during the nighttime. Figure (3) validates the presence of diverse crowd in Sydney Hyde Park during daytime and nighttime due to good illumination and variety of activities in the park. 

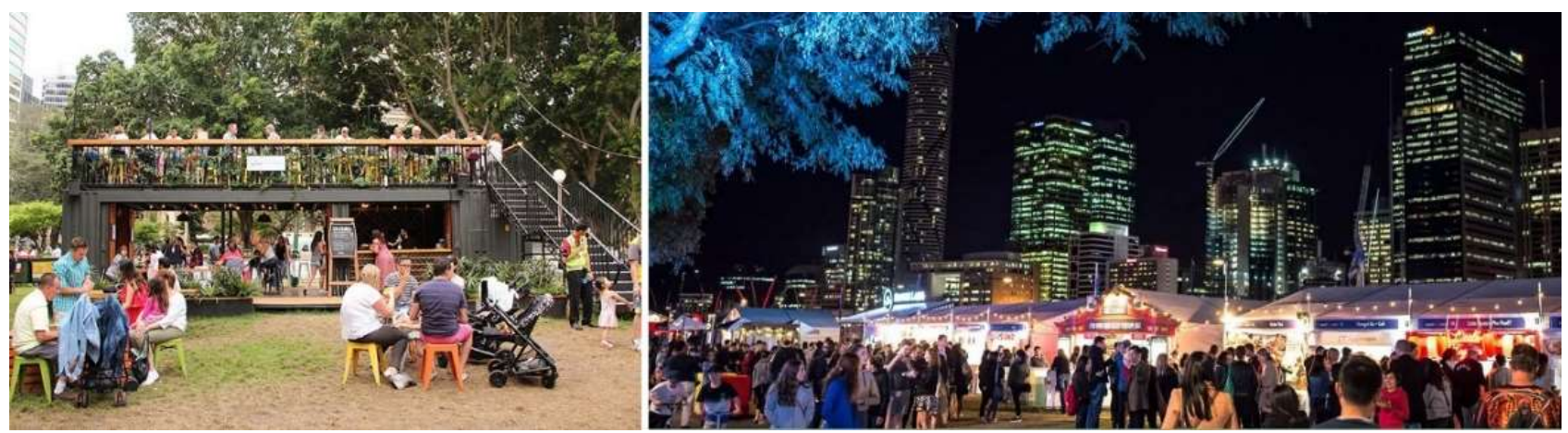

Fig. 3. Night noodle market at Sydney Hyde Park. (Source:

https://www.google.com/search?q=night + noodle + market + sydney+hyde+park, Retrieved on December $\left.24^{\text {th }}, 2019\right)$

\subsubsection{Convenience}

Character of the park is determined by its facilities, supporting features and their conditions. Several features of park can positively or negatively influence park use. Park amenities such as barbeques, seating areas, picnic tables, water fountains, lighting units, rubbish bins and bathrooms appear to be important in regardless of users' age [41-42]. Urban furniture should be compatible with the environment and the users' needs, giving the park a good image. Lack of maintenance influences usage of parks, it can be obvious in cleanliness of the park, characteristics of playing surfaces, lack of grass or poor quality of the sidewalks [41]. Figure (4) identifies some of the supporting features in parks.
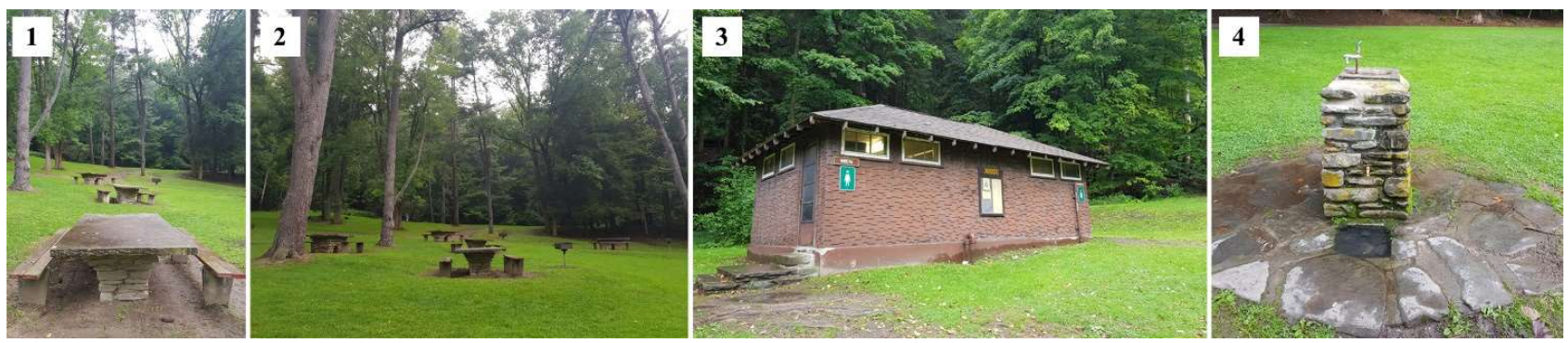

Fig. 4. Supporting amenities in Letchworth State Park, NY. (1,2): Picnic tables, (3): Bathrooms, (4): Drinking fountain. (Source: The researcher)

The relationship between place and people is defined as place attachment and has two domains; functional and emotional. It can be influenced by activity, individuals and features of the place. Place attachment encourages a sense of security [43]. It is linked to parks utilization, social interaction and proximity to visitors [44]. The functional attachment could be observed from the amount of familiarity, period of engagement, dependency, satisfaction and comfort. Users' sense of place in a park can be related to the activity they perform, their intensity of involvement or because they live near the park [45]. Frequency of visit, parks attraction, familiarity, emotional and functional attachment, park activities and facilities, satisfaction and social interaction; are indicators of place attachment [44]. Familiarity is an aspect that has an impact on environmental preference, visual access and wayfinding [46].

\subsubsection{Distinctiveness}

Parks form an imperative component in the identity of a place; reflecting the complexity of local landscape, heritage and culture, as they can be a key magnet of an area. A successful park usually reflects the identity and culture of the community. Public art in the parks enhances individuals' appreciation of the landscape [47]. Certain parks in famous cities are almost as iconic as the cities themselves-for 


\section{SJFA}

Scientific Journal of the Faculty of Fine Arts Alexandria University

instance, Hyde Park in London or Central Park in New York [48]. Uniqueness of parks can be through its functionality or accessibility [49]. Also physical attributes as; park size, maintenance, variety of amenities and activities, condition of park features and maintenance of the park, are associated with how vital the park is and its remarkability $[6,41,50]$.

Parks have an identifiable impact in terms of social interaction and have potential roles as social integrators [30,51]. Sociability is one of the most vital dimensions of parks creating a vivid strong relationship between the place and society. This factor can be easily measured through determining the level of different social groups' present in different hours of day and night [52]. Sociability has two dimensions; the ability to socialize and the environment. The opportunity to socialize is through an appealing design of park layout and facilities enhancing the social inclusion. The environment has an apparent reflection on user's satisfaction and is clarified through good maintenance of the park, absence of incivilities, park's view and location [23].

\subsection{Impact of time factor on vitality parameters of parks}

Time maybe thought of as a linear, unchecked, without beginning or end. It is tied to remarkable natural and human events; generations, seasons, moons and days. Time is discontinuous and linked with certain events. An environment is an emblem of past, present and future time. Past, present and future are simultaneously created and influence one another. Complexity of an urban space is derived from balancing between the conflicting views of the past and present [53]. Kevin Lynch was the first to introduce the temporal approach to the planning of urban spaces [54].

A social image of time should enlarge and vivify the present while increasing its figurative connections with the past, specially the future [53]. Parks play an important role in building environmentally sustainable cities. Thus examining the vitality of parks over time is fundamental, as time has become more valuable $[53,55]$. Time variation characteristics are often neglected leading to one perspective side when viewing urban vitality. Vitality concept points out to the idea of urban space vitality during the day formed by continuous human activities rather than gathering effect of people only during peak hours. Therefore, studying urban spatial and temporal vitality is needed providing a new way in alleviating the vitality concept [56].

Environment can be designed as organized in time or emblematic of time. There are number of methods available, one is the visible accumulations of the signs of past events, which makes the depth of historical time apparent. Another is the repetition of events showing the rhythmic of time. There are four distinct modes in which environmental change can be made into an esthetic experience; temporal collage is the juxtaposition of old and new events speaking of the passage of time and eloquent contrast; and by it, users visibly accumulate the rich traces of past time. By episodic design, users can create contrasting states that help organize time into patterns; deciduous trees are an example of this effect, as their summer and winter forms are varied, yet logically and visually connected. By direct display of environmental change, continuous modifications in the present are dramatized. The last is by exploiting the observer's motion, same effects are gained even in an unchanging environment [53].

The term urban vibrancy describes the attraction, diversity and accessibility of a place with time variability [57]. According to Montgomery (1998), vitality is what distinguishes successful urban areas as it refers to the number of people in and around the space, the pedestrian flow across different times of day and night, the uptake of facilities, the extent in which the place feels alive and the presence of cultural events and celebrations over the year [58,59]. A desirable image of an urban space is one that enlarges and celebrates the present while sustaining connections with past and future [53]. 
Current studies focus on influencing factors of urban vitality from only a static perspective although people are the fundamental reason behind formation of vitality, as it exists when activities and people are present [60]. The understanding of place requires different methods, all based on three factors; space, nature and time [61-62]. An environment that can be modified progressively is more remarkable than an environment that cannot be changed as it invites its own destruction [53]. Accordingly, urban spaces have to be self-associated with different times to obtain different results [62-63]. An environment that facilitates recalling is a way of linking the living moment with a wide span of time. The past can be shown in relation to the present [53].

\subsubsection{Impact of time on accessibility}

According to Lynch (1960), accessibility is a time issue but also depends on the attractiveness and identity of the itineraries [64]. Time of the day varies in ease of accessibility, for instance; during nighttime, location of public transportation stops should be appropriate in terms of visibility, safety, security and desirability [65]. It is found that travel distance has an exponential limiting effect on park visits [66]. Safety and lack of social barriers in relation to time have as much to do with accessibility as do vehicles and roads [53].

\subsubsection{Impact of time on legibility}

A fluid environment is one that responds quickly to shifts in actions and attention by its users. For example, the lighting in parks might be programmed to brighten during a vital event [53]. Light is the most important precondition for the society. The increase of artificial lighting increases the positive utilization of the urban space. There is a plausible connection between light and safety, and it has two dimensions; social safety as crime or fear of crime and road safety [67]. An environment may not accept cyclical change but dramatize it like the arrangement of night lighting to reverse the shadows of sun or activities, shelters and furnishings changed emphasizing shifts in seasons. Late hour activities are vivid when they occur in zones that are expected to be deserted [53]. Since most elements of the spatial environment cannot be changed, night show is a form of nighttime entertainment, a play of artificial light and recorded sound dramatizing the historic settings. Illumination deliberately shows direction and time, indicates large gatherings and crucial events as well as emphasizing the landmarks [53].

Environmental change can be in the form of light that goes on and off or change color, dim and brighten can pulse depending on underlying rhythm. During the nightlife; there are variety of approaches, which are; structural, social and economic. Structural dimension during nighttime includes legibility and convenience, while economic dimension is related to variety of activities and integration of facilities. Social interaction and liveliness are domains concerned by the social dimension. Consistency between night landscape and urban performance during the day and night is what defines dynamic vitality of an open space [65].

\subsubsection{Impact of time on convenience}

Light and climate are invariant visible forms of the environment. The remembered contrast between seasons is symbolically enhanced by recalling the previous state. For instance, the Japanese experts display spring pictures in the dark of the year and snow scenes in the spring. And since that trees act as a seasonal clock, a bare tree in a park evokes the winter and a tropical greenhouse in the snow brings summer to mind [53]. Parks provide cooling impact, and this phenomenon is termed as park cooling island (PCI) effect [68-69]. Climate and different seasons are an ecological variable and a physical parameter of urban spaces that alter users' perception and convenience due to factors of micro-climatic conditions as sunlight, wind, humidity and temperature [62,70]. Therefore, when planning green spaces; providing human comfort and reducing heat stress are predominant focuses [71]. 


\section{SJFA}

Scientific Journal of the Faculty of Fine Arts Alexandria University

Temporal limits for a certain behavior might help in controlling the timing of events in an urban space. New timing patterns can be initiated by introducing services or activities at some unusual hours or days, enhancing vitality of the park. It is conceivable that an activity timing can be altered augmenting the sequential character of the urban space. For social coordination between parks' users, increasing the range of timing choices is valuable creating a stable and coherent pattern that is shared by others and fits the requirements of the individuals. New sources of public enjoyment can assess individuals to be alive in over longer period of time and can change the chaotic urban landscape into legible and meaningful one [53].

\subsubsection{Impact of time on distinctiveness}

The old environment is usually seen as an opportunity for dramatic enhancement, becoming richer than its old state. One of the problems facing the revitalization of an old place is how to maintain continuity of image and association despite the physical and social upheaval to which the users have been exposed, this can be achieved by mixing between the old and new settings. And since image of the place is fundamental, its history should be interwoven with the history of the new settings. In a historic urban space, as historical parks, its setting should illustrate the full spectrum of its culture and not only the great moments of the period. This clarifies that parks with historical features can have an impact on how distinctive the park is. Saving something indicative of the old ambience; its scale, plantings, spaces or pathways, will help in stimulating the vitalization process of the environment [53].

The external built environment illustrates a role in building and supporting the image of time. The same environment can have a different influence on the users because of time. Exposure of successive eras of history and the insertion of new materials that reinforced the past by allusion or contrast will give positive image to the environment, producing a setting more densely packed with references to the stream of time rather than a setting that never changes. Events of the recent past can be commemorated, also elements that need to be in retention in parks have to be symbolically rich or conveying a sense of total ambience of the past. Historic structures seem mostly impressive in two ways; either quite isolated or in intimate contact with the contemporary life and embedded in the center [53].

\subsection{Conclusion}

Analyzing the rhythms of time in parks devoting attention to the duration, the density and the temporal sequence of activities is important in issuing a dynamic vital park. Liveliness of the park throughout the time of days or seasons is what keeps it dynamic. In order to achieve vitality definition in parks; accessibility, legibility, convenience and distinctiveness factors should be acknowledged in relation to physical and social attributes. 
Table. 1. Framework of time impact on vitality of parks. (Source: The researcher)

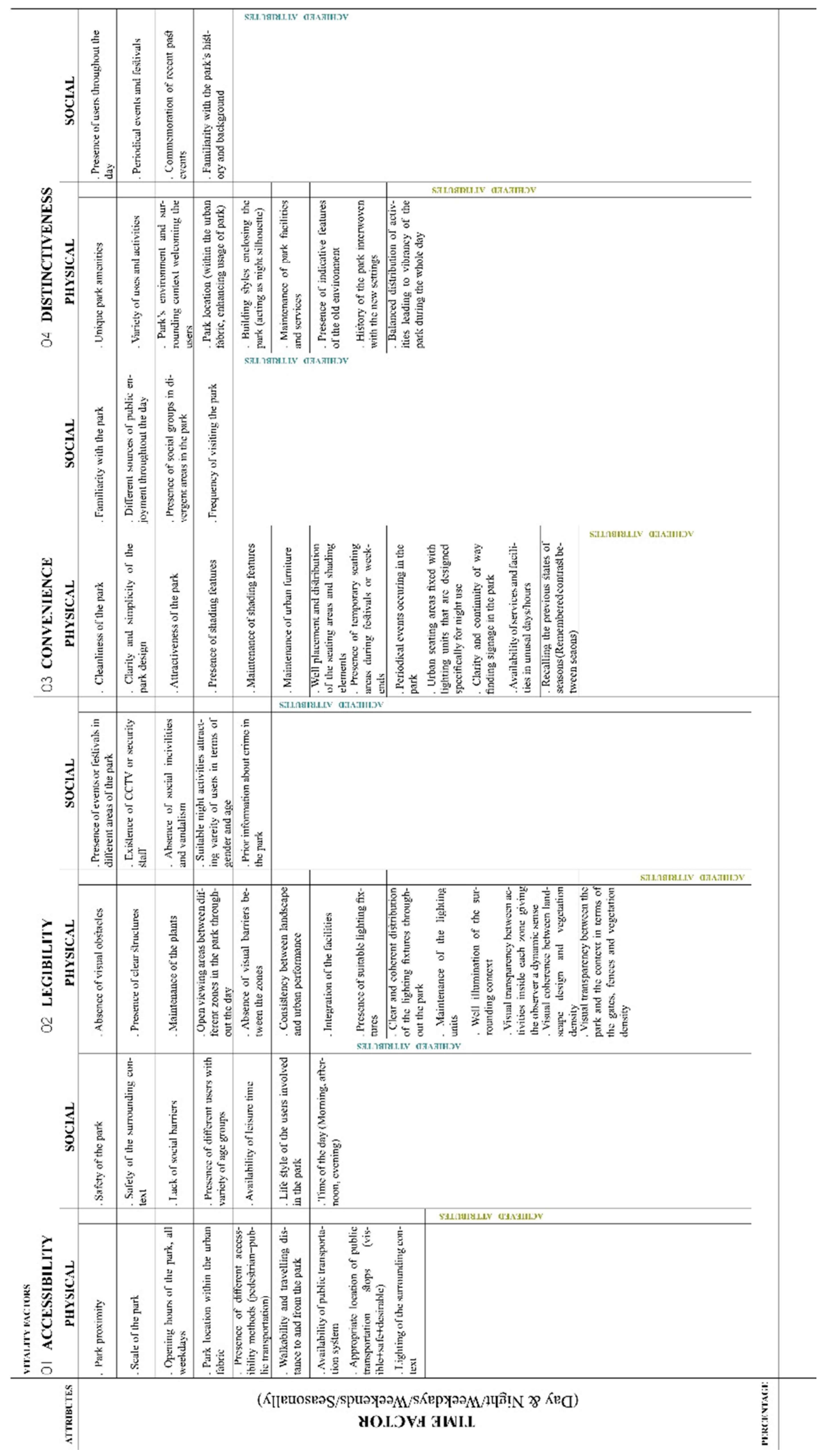




\section{ANALYTICAL EXAMPLES}

Two different examples of parks with different amenities are selected; Büyük Park in Izmir, Turkey and Tantolunden Park in Stockholm, Sweden. The selection criteria rely on certain variables which are diversity of geographical location, culture and scale, as well as availability of data. The parks are evaluated according to the framework concluded from the literature review. The examples measure the impact of time on vitality parameters with respect to the physical and social attributes of each factor.

\subsection{BUYUK PARK in IZMIR, TURKEY}

\subsubsection{Description}

The city of Izmir, is located in the west of Turkey and the third largest metropolitan city of the country. Its surface area is $12.012 \mathrm{~km}^{2}$ [72]. Izmir has a coastal city identity and is an economically and socially dynamic city due to its location, climate and being home to different cultures [73]. Izmir contains the 3rd largest population and has 9 districts; Balçova, Bornova, Buca, Çiğli, Gaziemir, Güzelbahçe, Karşıyaka, Konak and Narlıdere [74].

Büyük Park is located in the center of the Bornova district which is in northeast of Izmir [75]. The park was first established in 1934 with a total area of $38,150 \mathrm{~m}^{2}$. It is Bornova's largest and Izmir's third largest park. It has a unique location, within the city center, and physical opportunities enhancing residents to use it frequently [46,75]. It is bounded by Ege university main campus from the South, a historical landmark known as Peterson Pavilion and Bornova public education center from the North, Ataturk library from the East and a primary school in the West. Büyük Park is surrounded completely by mixed uses as shops, cafés, restaurants at the ground level and residential uses on top. It creates a shortcut between different regions of the city center with plenty of public facilities [46].

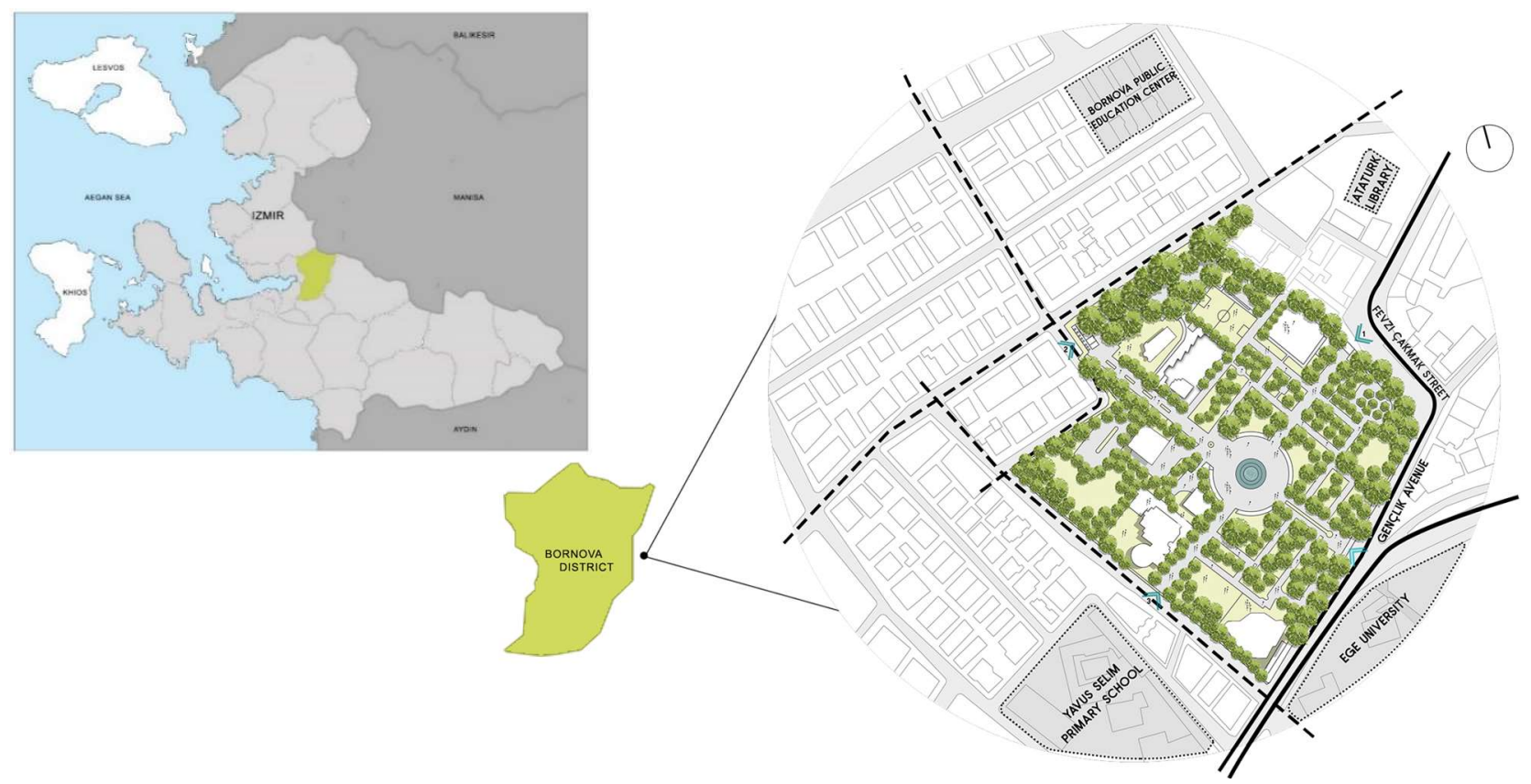

Fig. 5. Location of Izmir and Büyük Park. (Source: The researcher)

After the Izmir's republication period in 1923, gardens of private residences were transformed into public promenades then to public parks. Büyük Park was transformed from a cemetery into public park 
in 1934 by Rahmi Bey, former governor of Izmir and the first founder of the park. After 10 years of the republic, Governor Kazim Dirik Pasha was interested in developing the park [46,76].

\subsubsection{Impact of time on vitality factors in Buyuk park}

\subsubsection{Accessibility}

The park is located on the shopping axis in the town center and surrounded by socio-cultural venues, this advocates users' accessibility and the park's usage most of the time throughout the day. Due to the livability of the surrounding context, this gives the users sense of safety during day and night [46]. It is easily approachable by public transportation as bus, metro or train. It is surrounded by variety of facilities within a walkable distnace of 10 minutes helping in the liveliness of the surrounding, therefore facilitating the accessibility to the park during different time of the day.

The 4 entrances/exits speculate the concept of a friendly pedestrian park, as there is 1 main entrance and 3 secondary. The main one is directly linked with the park's main spine and ornamental pool, while the entrance (1) is near the playground zone, entrance (2) is considered perpendicular on the main entrance/exit leading to the open air theatre and entrance (3) can be contemplated as a specified entrance to the wedding hall for gatherings and events, as shown in figure (6).

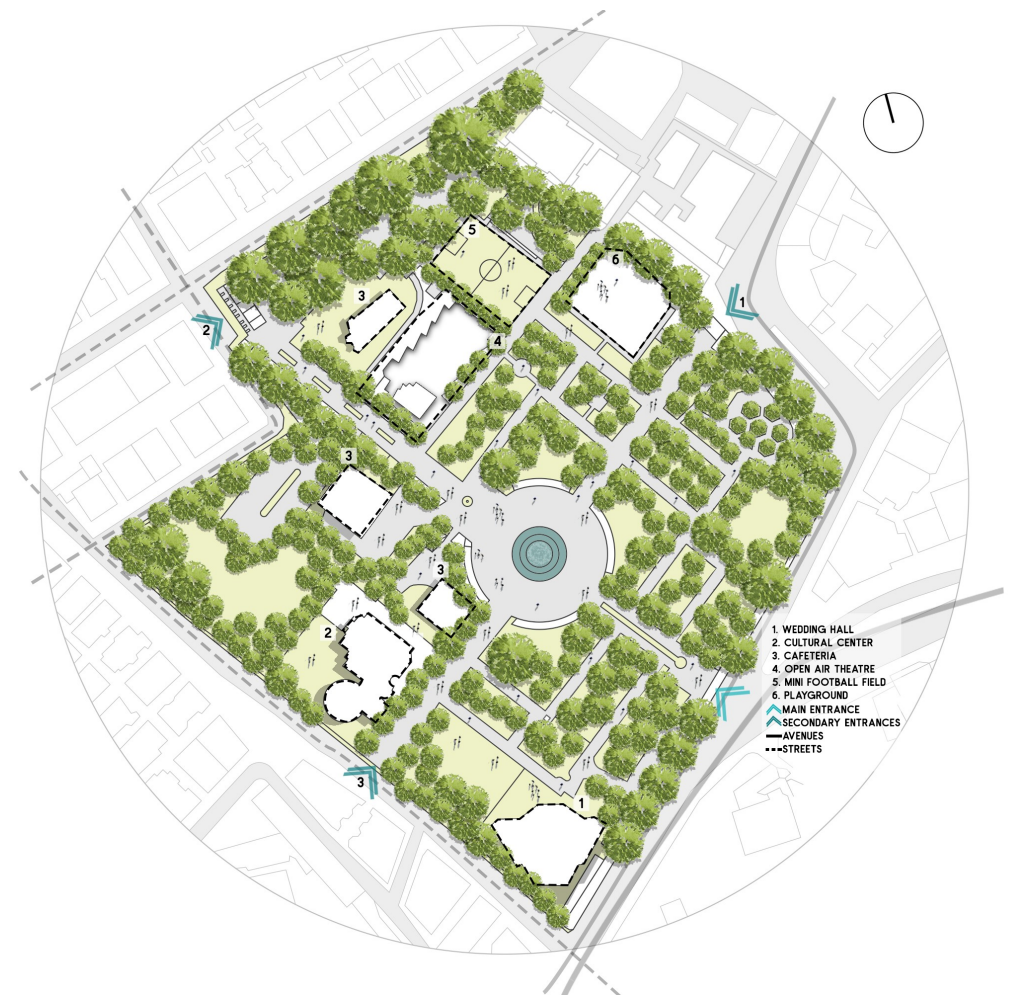

Fig.6. Accessibility of Büyük park in relation to the surrounding street network. (Source: The researcher)

\subsubsection{Legibility}

The park has sufficient lighting at night and does not have security staff or CCTVs, but the multifunctionality of the closed spatial uses in the park provides a more secure environment during both daytime and nighttime. It also has good visibility level due to the absence of visual obstacles in the park. In some zones, users noticed some concealed areas and views due to the tree density which gives them sense of unsafety during the daytime and nighttime [46]. 


\section{SJFA}

Scientific Journal of the Faculty of Fine Arts Alexandria University

Facilities are well distributed and integrated in the park, where each zone has disparate activity, allowing the users to feel more safe. The differentiation in the facilities grant the park vibrancy during different time of the day. The park's design enables users to have visual coherence between the zones [46]. Absence of social incivilities and vandalism enhances the park to be more legible and safe. The open air theatre, cultural center and wedding hall strengthen the variety of activities during the nighttime as well as the daytime [77].
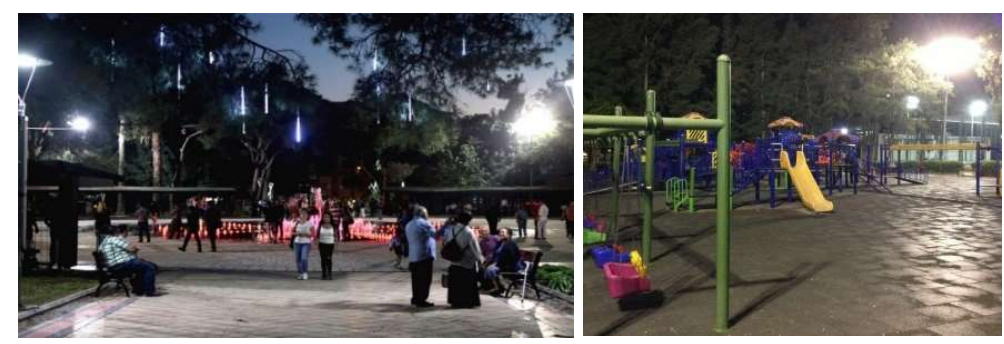

Fig. 7. Lighting at Büyük Park in night (Source: https://www.google.com/search?q=buyuk+park, Retrieved on February

$$
\left.8^{\text {th }}, 2020\right)
$$

\subsubsection{Convenience}

Maintenance of equipment provided in the parks plays a crucial role in the park usage, and since users in Büyük Park showed a high ratio in visiting the park for children playing zone, this reveals that park facilities are well-maintained [77]. The park has been completely renovated, the existing fountain, walking pathways, children's playing area and lighting poles [78]. Büyük Park can be considered as a well-maintained park regarding its urban furniture, shading elements, green areas, pavements and cafés, as shown in figure (8) [46]. As for the signage, it has some signs, as those indicating not to enter the ornamental pool or not to use motorcycle in the park. However, it lacks 'You are here' maps for ease of wayfinding and rule signs for preventing drug users or social incivilities [46]. Signage are not considered visible as they are not designed for the night usage as well as the lack of lighting units around them. Users are satisfied with the park's physical conditions, the designed landscape features, the variety of activities, open and closed spatial uses it offers and its central location in the downtown [77].
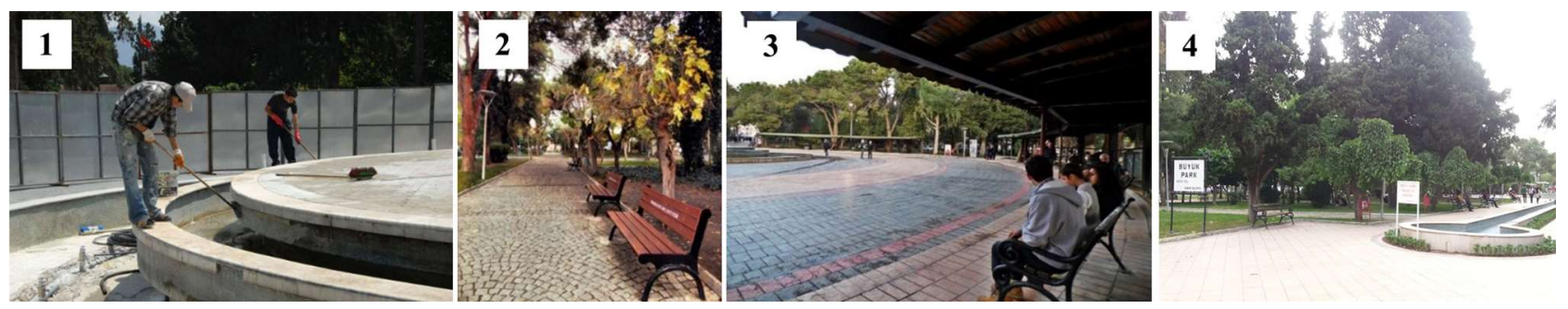

Fig. 8. (1) Fountain, (2-3) Benches and shading features, (4) Signage (Source: https://www.google.com/search?q=buyuk+park,

Retrieved on February $\left.8^{\text {th }}, 2020\right)$

The most favorite visiting time was in the afternoon. Visitors frequently used the park daily or twice a week. Duration of the stay was also statistically significant to measure. Almost more than half of the respondents visited the park for less than an hour or 1-2 hours and the rest stayed in the park for 3-4 hours. Frequency of visiting parks had a remarkable effect on user's safety. Users visiting the park everyday perceived it as more safety from crime and were more satisfied with its design and amenities. One of the reasons enhancing them to visit it more frequent is the variety of cultural and social activities that occur in the park [46]. 


\subsubsection{Distinctiveness}

Büyük Park offers variety of amenities and facilities. It consists of 3 cafés, a cultural center, a wedding hall, an open-air theatre, a playground, a mini football playing area and a refreshment area with an ornamental pool in the center of its axes, as shown in figure (9). Since there are some facilities in the park that require night working hours as the wedding hall, cultural center and the open-air theatre, this height
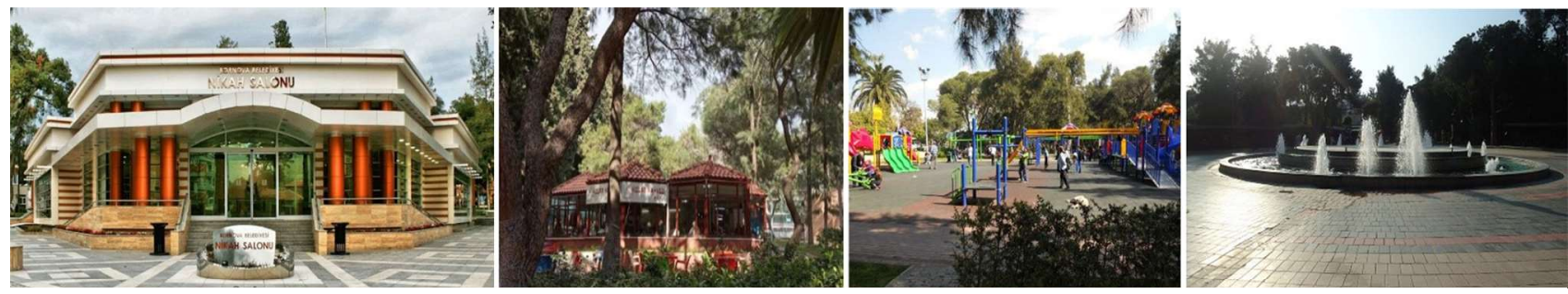

Fig. 9. Facilities of Büyük park. (Source: : https://www.google.com/search?q=buyuk+park,

Retrieved on February $\left.8^{\text {th }}, 2020\right)$

The park is full of historical elements that dates back to different years. Uğur Mumcu Culture and Art Center dates back to 1993 and was named in the honor of a Turkish investigated journalist who died in 1993. It brings together all those interested in cinema, philosophy, painting, literature and visual arts [79]. The Ayfer Feray open air theatre was named after the Turkish actress, Ayfer Feray, who died in 1994 [80]. The Bornova municipality, city hall, is located inside the park on its edges, giving the park a unique image and high sense of safety. There are two statues, one in the axe of the park, for Mustafa Kemal Atatürk who was a former president of Turkey since 1923 until his death in 1938 and the other statue is for Rahmi Bey, former governor of Izmir and the founder of Büyük Park in Bornova [76], sitting on a bench in the central plaza of the park, figure (10). All these amenities together with the park's unique location enhance the users to be more socially inclusive and raise the park's identity.
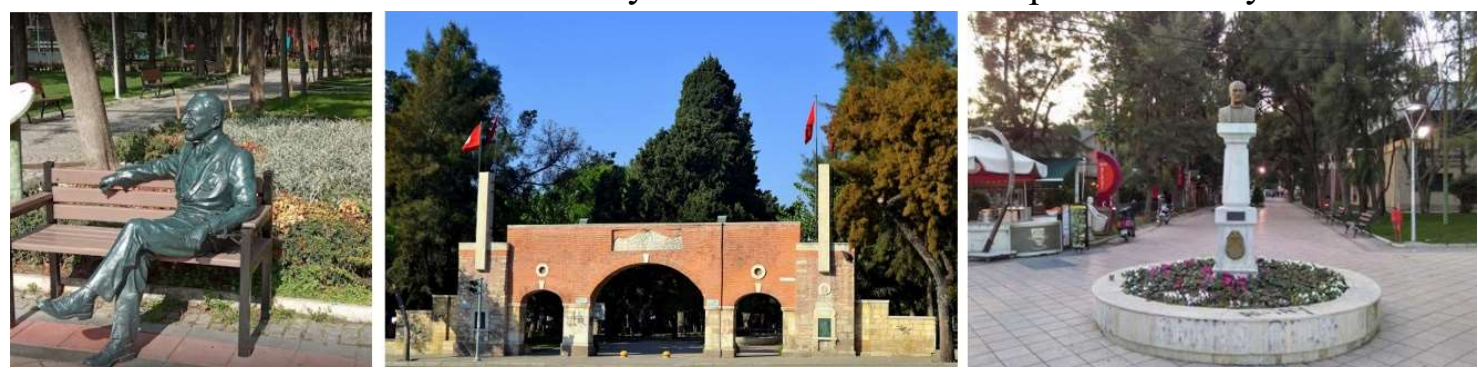

Fig. 10. Statues and the park's main entrance gate. (Source: : https://www.google.com/search?q=buyuk+park,

Retrieved on February $8^{\text {th }}, 2020$ )

\subsubsection{Assessment framework}

Table (2) clarifies the framework implied on Büyük Park in Izmir concluding a final percentage, that indicates the importance of time impact for each of the four vitality factors. 


\section{SJFA}

Scientific Journal of the Faculty of Fine Arts Alexandria University

Table. 2. Büyük Park achievement points in comparison to the framework. (Source: The researcher)

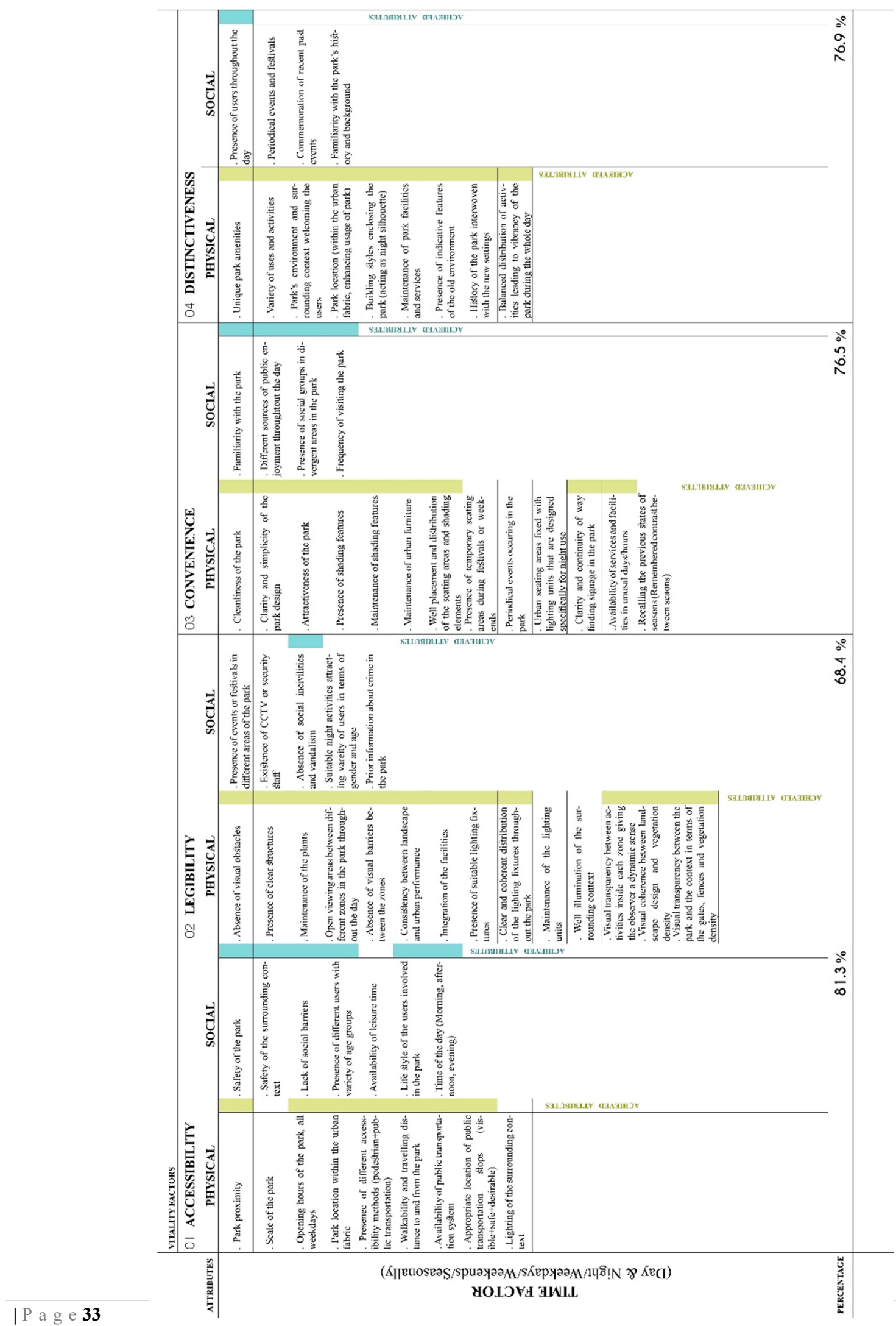




\section{CONCLUSION}

Based on the literature review, vitality of public parks depends on four mandatory factors which are accessibility, legibility, convenience and distinctiveness, where each factor covers physical and social attributes. Time has proven to have an influential impact on vitality parameters of public parks, regardless the park's scale, creating a dynamic form in the environment and different image regarding the user's perception. This is interpreted in the analytical example, Büyük Park in Izmir.

Büyük Park showed to be a dynamic park with a legible design and layout which assists in facilitating the users to engage more with its environment. Time has a great impact on accessibility attributes with $81.3 \%$, which is the highest percentage compared to the four vitality factors, while the least impact is on legibility with $68.4 \%$. As for convenience and distinctiveness, time factor considered to have almost the same importance regarding their attributes $76.5 \%$ and $76.9 \%$ respectively.

Time has an apparent consequences and effect in urban planning and user behaviour. Therefore, it is highly recommended to take into due account time factor as an imperative aspect when tackling the vitality of any public park for enhanced users' social and physical behaviour, as well as raising the benchmark of parks' perfomance. This will give more reliable results and outcomes when discussing the vitality of public parks.

\section{REFERENCES}

1. Rouhi, M., Monfared, M. R., \& Forsat, M. (2016). Measuring Public Satisfaction on Urban Parks (A case Study: Sari City). Journal of History Culture and Art Research, 458.

2. Jalaladdini, S., \& Oktay, D. (2012). Urban Public Spaces and Vitality: A Socio-Spatial Analysis in the Streets of Cypriot Towns. Procedia - Social and Behavioral Sciences 35, 665-667.

3. Zaidin, N., Tukiman, I., Shahli, F. M., \& Hussain, M. R. (2016). Place Attachment in Relation to Urban Street Vitality. International Transaction Journal of Engineering, Management, \& Applied Sciences \& Technologies, 1213.

4. Zakerhaghighi, K. (2019). Urban vitality evaluation in Vali Asr crossroad on the basis of activity patterns. The Scientic Journal of NAZAR research center (Nrc) for Art, Architecture \& Urbanism, 5-11.

5. Azeri, A. R., Aladini, M., \& Mozhdehi, M. A. (2018). Investigating the Role of Space Factors in Promoting Vitality for Designing Sports Complex. Civil Engineering Journal. Vol. 4, No. 7, 1740-1741.

6. Yan, Y., Zhu, J., Lu, H., Zheng, T., Rong, Yuejing, W. C., . . . Tang, L. (2020). Vitality of Urban Parks and Its Influencing Factors from the Perspective of Recreational Service Supply, Demand, and Spatial Links. International journal of environmental research and public health, Vol. 17, Issue No. 1615, 1-4.

7. Isiklar, S. (2017). Vitality of the cities. International Journal of Architectural Engineering Technology, 18,22.

8. ORUÇ, G., \& GIRITLIOĞLU, C. (2007). The evaluation of urban quality and vitality of the Istanbul historical peninsula- Eminönü district. ITU A|Z. VOL: 5 NO: 1, 99-100.

9. Karami, S., Fakhrayee, A., \& Karami, S. (2015). Studying the Effect of Accessibility and Vitality on Urban Space Efficiency in Iran (Case Study: Hamadan City). International Journal of Architecture and Urban Development, Vol.5, No.1, 36-37.

10. Nasri, S. R., \& Kolour, S. I. (2015). Evaluation of effective factors on vitality of public spaces of new cities with emphasis on identity concept. Science Journal (CSJ), Vol. 36, No: 6, 513-514.

11. Xia, C., Zhang, A., Chu, J., Lin, J., Li, W., \& Wu, J. (2019). Portraying urban landscape: A quantitative analysis system applied in fifteen metropolises in China. Sustainable Cities and Socities, Vol. 46.

12. Hikmah, Nday, R. U., \& Manu, A. K. (2018). Vitality of Public Open Space (Case Study: Taman Nostalgia Kupang). Mediterranean Journal of Social Sciences. Vol. 8, No. 4, S1, 125.

13. Zhang, A., Xia, C., \& Yeh, A. G.-O. (2020). Analyzing spatial relationships between urban land use intensity and urban vitality at street block level: A case study of five Chinese megacities. Landscape \& Urban Planning, Vol. 193, 2-3.

14. Zakerhaghighi, K. (2019). Urban vitality evaluation in Vali Asr crossroad on the basis of activity patterns . The Scientic Journal of NAZAR research center (Nrc) for Art, Architecture \& Urbanism, 5-11.

15. Rastegar, N., Ahmad, M., \& Malek, M. (2014). Factors affecting the vitality of streets in downtown Johor Bahru City. Indian Journal of Scientific Research, Vol. 07, Issue NO. 01, 4-5. 
16. Wu, C.-K., \& Song, L.-Y. (2017). A case for inclusive design: Analyzing the needs of those who frequent Taiwan's urban parks. Applied Ergonomics, Vol. 58, 254.

17. Aval, H. S. (2015). Urban space designing for more vitality (Case study: Ferdosi. St in Zabol). Science Journal, 4154-4156.

18. Razak, M., Othman, N., \& Nazir, N. (2016). Connecting People with Nature: Urban Park and Human Well-being. Procedia - Social and Behavioral Sciences, Vol. 222, 476.

19. Cohen, D., Marsh, T., Williamson, S., Derose, K. P., Martinez, H., Setodji, C., \& McKenzie, T. (2009). Parks and physical activity: Why are some parks used more than others? Preventive Medicine, 2.

20. N, L., JY, L., HW, Y., T, S., \& Y, L. (2014). Analysis on accessibility of urban park green space: the case study of Shenyang Tiexi District. The Journal of Applied Ecology, Issue No. 10.

21. Swank, B. M., Mozaffar, F., Faizi, M., \& Rayatidamavandi, M. (2016). Assessing Design Principles of Urban Parks in Iran for Promoting Women's Satisfaction. International Journal of Humanities and Cultural Studies, Vol. 03, Issue No. 02, 1461-1463.

22. Liang, H., Chen, D., \& Zhang, Q. (2017). Walking accessibility of urban parks in a compact megacity. Proceedings of the Institution of Civil Engineers - Urban Design and Planning, Vol. 170, Issue No. 02, 2,6 .

23. Sakip, S. R., Akhir, N. M., \& Omar, S. S. (2015). Determinant Factors of Successful Public Parks in Malaysia. Procedia-Social and Behavioural Sciences, Vol. 170, 422-428.

24. Begum, H., \& Sharna, F. K. (2018). Factors Influencing Public Accessibility to Community Open Spaces in Dhaka City: A Case Study of Mirpur Budhhijibi Complex in Dhaka. The International Journal of Social Sciences and Humanities Invention, Vol. 05, Issue No. 05, 4759-4760.

25. Rao, P., \& Puntambekar, K. (2014). Evaluating the urban green space benefits and functions at macro, meso and mirco level: Case of Bhopal City. International Journal of Engineering Research \& Technology, Vol. 03, Issue No. 06, 360-361.

26. Rahman, K. M., \& Zhang, D. (2018). Analyzing the Level of Accessibility of Public Urban Green Spaces to Different Socially Vulnerable Groups of People. Sustainability, Vol. 10, 3,5.

27. Zhou, W., \& Zhang, S. (2018). Recreational visits to urban parks and factors affecting park visits: Evidence from geotagged social media data. Landscape and urban planning, 1.

28. Wang, D., Brown, G., \& Liu, Y. (2015). The physical and non-physical factors that influence perceived access to urban parks. Landscape and Urban Planning, Vol. 133, 53.

29. Wang, D. (2015). Rethinking Planning for Urban Parks: Accessbility, Use and Behaviour. 1,18,23.

30. Ujang, N., \& Moulay, A. (2016). Legibility of neighborhood parks and its impact on social interaction in a planned residential area. International Journal of Architectural Research, Vol. 10, Issue No. 01, 185-188.

31. Özkan, D. G., Akyol, D., \& Çiğdem, A. (2018). Legibility of Neighborhood Park: A Case Study of Trabzon City Centre. The Eurasia Proceedings of Educational and Social Science, Vol. 11, 171.

32. Nunes, D. V., \& Vale, D. S. (2015). Physical characteristics that influence urba ndesign qualities of livable and walkable urban places: Lessons from Portuguese cities. Making cities livable: Achieving green healhy cities, (p. 5). Bristol, UK.

33. Mohamed, A. A. (2010). Spatial conditions for sustainable communities: The case of infromal settlements in GCR. 43-44.

34. Moulay, A., Said, I., \& Ujang, N. (2017). Legibility of neighborhood parks as a predicator for enhanced social interaction towards social sustainability . Cities, Vol. 61, 58.

35. Swank, B. M., Mozaffar, F., Faizi, M., \& Rayatidamavandi, M. (2016). Assessing Design Principles of Urban Parks in Iran for Promoting Women's Satisfaction. International Journal of Humanities and Cultural Studies, Vol. 03, Issue No. 02, 1461-1463.

36. Maruthaveeran, S., \& Konijnendijk, C. C. (2015). Fear of crime in urban parks - What the residents of Kuala Lumpur have to say? Urban Forestry \& Urban Greening, Vol. 14, Issue No.03, 702.

37. Mahrous, A. M., Moustafa, Y. M., \& Abou El-Ela, M. A. (2018). Physical characteristics and perceived security in urban parks: Investigation in the Egyptian context. Ain Shams Engineering Journal, Vol. 09, 3055-3056.

38. Hashim, N. H., Thani, S. K., Jamaludin, M. A., \& Yatim, N. M. (2016). A Perceptual Study on the Influence of Vegetation Design towards Women's Safety in Public Park. Procedia - Social and Behavioral Sciences, Vol. 234, 280-283.

39. Konijnendijk, C. C., \& Maruthaveeran, S. (2014). A socio-ecological exploration of fear of crime in urban green spaces - A systematic review. Urban Forestry \& Urban Greening, Vol. 13, 4-5.

40. Łopuszyńska, A., \& Zielińska, M. B. (2019). Lighting of urban green areas - the case of Grabiszyn Park in Wrocław. Searching for the balance between light and darkness through social and technical issues. E3S Web of Conferences 100 (pp. 1-4). EDP Sciences. 
41. Mccormack, G. R., Rock, M., Toohey, A. M., \& Hignell, D. (2010). Characteristics of Urban Parks Associated with Park Use and Physical Activity: A Review of Qualitative Research. Health \& Place, Vol. 16, 712-723.

42. Kara, B., Tuncay, H. E., \& Deniz, B. (2011). Investigating recreational qualities of the parks in Aydin. ProcediaSocial and Behavioral Sciences, Vol. 19, 160.

43. Ayeghi, A., \& Ujang, N. (2014). The impact of physical features on user attachment to Kuala Lumpur. Malaysian Journal of Society and Space, Vol. 10, Issue No. 03, 44-46.

44. Ujang, N., Moulay, A., \& Zakariya, K. (2015). Sense of Well-Being Indicators: Attachment to public parks in Putrajaya, Malaysia. Procedia - Social and Behavioral Sciences, Vol. 202, 487-493.

45. Rossi, S. D. (2014). Factors affecting people-park relationships in peri-urban national parks. 7,8,11,38.

46. Zengel, R., \& DOĞRUSOY, İ. T. (2017). Analysis Of Perceived Safety In Urban Parks: A Field Study In Büyükpark and Hasanağa Park. METU Journal of the Faculty of Architecture (34:1), 63-66.

47. Cowan, R., Hill, D., \& Chapman, D. (2005). Start with the park: Creating sustainable urban green spaces in areas of housing growth and renewal. London: CABE space.

48. Li, C.-L. (2020). Quality of life: The perspective of urban park recreation in three Asian cities. Journal of Outdoor Recreation and Tourism, Vol. 29, 1.

49. Gu, X., Li, Q., \& Chand, S. (2020). Factors influencing residents' access to and use of country parks in Shanghai, China. Cities, Vol. 97, 1.

50. Cohen, D., Marsh, T., Williamson, S., Derose, K. P., Martinez, H., Setodji, C., \& McKenzie, T. (2009). Parks and physical activity: Why are some parks used more than others? Preventive Medicine , 2.

51. Sreetheran, M. (2017). Exploring the urban park use, preference and behaviours among the residents of Kuala Lumpur, Malaysia. Urban Forestry \& Urban Greening, Vol. 25, 85.

52. Soltanian, F., \& Mohammadi, A. (2015). Study of characteristics of urban public open spaces based on social interaction (Case study: Salavatabad's 3-kilometer route). European Online Journal of Natural and Social Sciences 2015, Vol. 04, Issue No. 03, 554-555.

53. Lynch, K. (1985). What time is this place? Cambridge, Massachusetts: The MIT press, Massachusetts Institute of Technology .

54. Mareggi, M. (2013). Space-Time Design of the Public City. London: Springer Science+Business Media Dordrecht.

55. Su, S., Li, Z., Wei, H., Wu, Y., Wang, W., \& Qu, C. (2019). Impact of community deprivation on urban park access over time: Understanding the relative role of contributors for urban planning. Habitat International, Vol. 92.

56. Zhang, L., Long, Y., \& Liu, S. (2019). Urban Vitality Area Identification and Pattern Analysis from the Perspective of Time and Space Fusion. Sustainability, Vol. 03, 1-3.

57. Wu, C., Ye, X., Ren, F., \& Du, Q. (2018). Check-in behaviour and spatio-temporal vibrancy: An exploratory analysis in Shenzhen, China. Cities, Vol. 77, Issue No. , 104.

58. Montgomery, J. (1998). Making a city: Urbanity, vitality and urban design . Journal of Urban Design, Vol. 03, Issue No. 01, 96 .

59. Hagenbjörk, L. (2011). An analyse of Chinese urban public space-Beijing as an example. 21.

60. Xu, X., Guan, P., Xu, X., Ren, Y., Wang, W., \& Xu, N. (2018). The cause and evolution of urban street vitality under the time dimension: Nine cases of streets in Nanjing City, China. Sustainability, Vol. 10, 2.

61. Hague, C., \& Jenkins, P. (2004). Place Identity, Participation and Planning. London: Routledge.

62. Ngesan, M. R., Abdul Karim, H., \& Zubir, S. S. (2018). Relationship between Nighttime Leisure Behaviour and Urban Park Setting in Shah Alam . Asian Journal of Behavioural Studies, Vol. 03, Issue No. 09, 175.

63. Seamon, D., \& Sowers, J. (2008). Place and Placelessness (1976): Edward Relph. In E. Relph, Key Texts in Human Geography. London: SAGE Publications Ltd.

64. Talavera, R. (2012). Improving pedestrian accessibility to public space through space syntax analysis. 8th Space Syntax Symposium (p. 2). Santiago de Chile: PUC.

65. Momenian, A., \& Zekavat, M. (2012). Rehumanasing Urban Space for Night Activities with Particular Reference to Principal 24 hours Cities in Iran. Research Journal of Applied Sciences, Engineering and Technology, Vol. 4, Issue No. 23, 5056-5061.

66. Tu, X., Huang, G., Wu, J., \& Guo, X. (2020). How do travel distance and park size influence urban park visits? Urban Forestery \& Urban Greening, Vol. 52, 1.

67. Pottharst, M., \& Konecke, B. (2013). Space-Time Design of the Public City. London: Springer Science+Business Media Dordrecht.

68. Jia, B., \& Qiu, K. (2020). The roles of landscape both inside the park and the surroundings in park cooling effect. Sustainable Cities and Society, Vol. $52,2$.

69. Prabhakaran, D., Mukherjee, D., Safraj, S., Tayyab, M., Roopa, S., Patel, S. A., . . . Tandon, N. (2017). Park availability and major depression in individuals with chronic conditions: Is there an association in urban India? Health \& Place, Vol. 47, 55-56. 
70. Setyowati, E., Harani, A. R., \& Falah, Y. N. (2013). The Application of Pedestrian Ways Design Concepts as an Implementation of Sustainable Urban Open Spaces. Procedia - Social and Behavioral Sciences 85, 346-350.

71. Nasir, R. A., Ahmad, S. S., \& Ahmed, A. Z. (2013). Physical Activity and Human Comfort Correlation in an Urban Park in Hot and Humid Conditions . Procedia - Social and Behavioral Sciences, Vol. 105, 599.

72. Yilmaz, E. S., \& Yilmaz, S. (2019). A review of urbanization, pollution and biodiversity in Izmir. International Journal of Environmental Trends (IJENT), Vol. 03, Issue No.01, 32-33.

73. Municipality, I. M. (2020, April 15). The city of beauty and fertility . Retrieved from Imzir Metropolitan Municipality: http://www.izmir.bel.tr/CKYuklenen/icerik_sayfalari/adayinizmir_2018_08.pdf

74. Nurlu, E., Kara, B., \& Sarıçam, S. (2011). The role of education on environmental consciousness: A case study in Izmir, Turkey. Journal of food, agriculture and environment, Vol. 09, Issue No.02, 681.

75. Turel, H. S., Yigit, E. M., \& Altug, I. (2007 ). Evaluation of elderly people's requirements in public open spaces: A case study in Bornova District (Izmir, Turkey). Building and Environment, Vol. 42, 2037-2039.

76. ŞAŞMAZ, E. (2020, April 16). BIG PARK - BORNOVA. Retrieved from erolsasmaz.com: https://www.erolsasmaz.com/?oku=968

77. ZENGEL, R., \& DOĞRUSOY, İ. T. (2014). The importance of sociocultural habits in park design, leisure behaviour and user satisfaction. A comparative study on two parks in Izmir, Turkey. Journal of Settlements and Spatial Planning, Vol. 05, Isuue No. 02, 107-115.

78. SonDakika. (2020, April 15). Bornova Big Park Renovated. Retrieved from SonDakika: https://www.sondakika.com/haber/haber-bornova-buyuk-park-yenilendi/

79. Foundation, U. M. (2020, April 15). About the foundation. Retrieved from Uğur Mumcu Researcher Journalism Foundation: http://www.umag.org.tr/tr/vakif/15/vakif-hakkinda

80. Yazer, H. (2020, April 15). Ayfer Feray. Retrieved from tsa 'Center for Turkish Cinema Studies' : https://www.tsa.org.tr/en/kisi/kisibio/538/ayfer-feray 


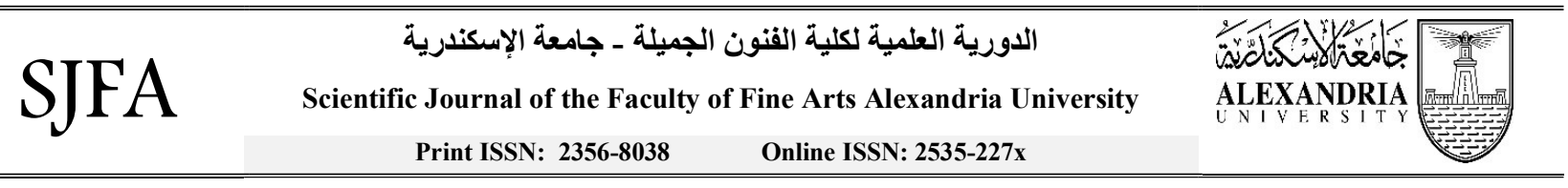

\title{
الإطار التقييمي لعامل الزمن في حيوية المتززهات العامة
}

\author{
يسر ا مجاهد 1، علاء الدين سرحان، ياسر فرغلي2
}

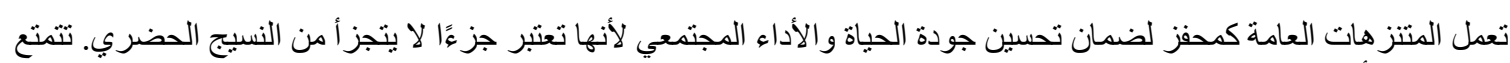

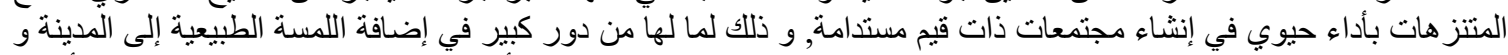

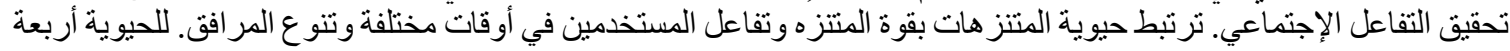

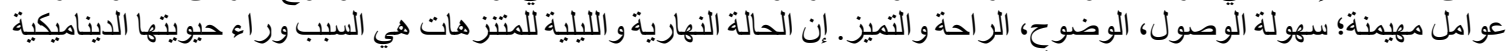

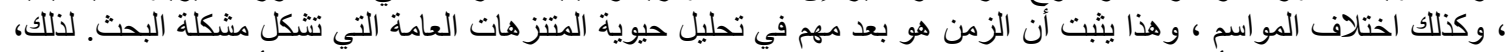

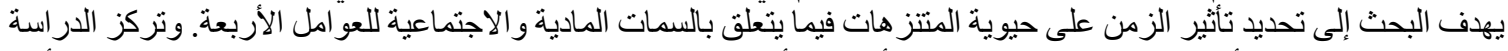

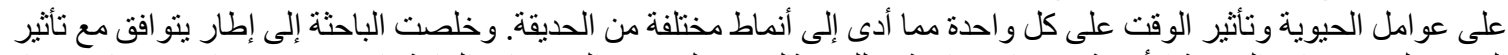

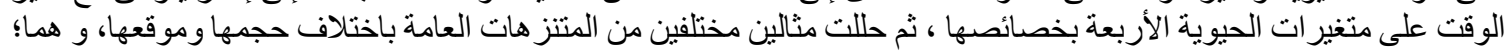

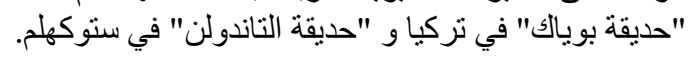

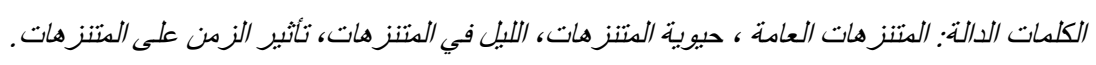

1امدرس مساعد غير متفرغ، قسم الهندسة المعمارية والتصميم البيئي، الأكاديمية العربية للعلوم و التكنولوجيا و النقل البحري، أبوقير، الإسكندرية، مصر yosramegahed@gmail.com 2 أستاذ، قسم الهندسة المعمارية والتصميم البيئي، الأكاديمية العربية للعلوم والتكنولوجيا والنقل البحري، أبوقير، الإسكندرية، مصر 